\title{
Entrevista al Dr. Manuel Burga, rector de la Universidad de San Marcos
}

Recibido: 19/02/2020

Aprobado: $20 / 05 / 2020$

Publicado: 25/08/2020
Humberto Rodríguez Pastor

Universidad Nacional Mayor de San Marcos <hrodriguez2541937@hotmail.com>

Por conocer que el doctor Manuel Burga Diaz, reciente electo rector de la Universidad Nacional Mayor de San Marcos, tiene antecesores chinos, en Oriental se consideró conveniente conversar con él. Interesaba que nos diga algo sobre los chinos del valle del Jequetepeque, donde se encuentra Chepén, activo pueblo norteño del departamento de La Libertad donde el rector nació hace algo más de medio siglo. Tuvimos en cuenta además que el Dr. Burga fue autor de la obra De la encomienda a la hacienda capitalista. El valle del Jequetepeque del siglo XVI al XX. Era, pues, evidente que podia decirnos bastante sobre lo que habia averiguado como historiador o de lo que recordaba por sus propias experiencias personales de esa importante colonia asiática de Chepén y del valle.

Con este motivo y revisando viejos ejemplares de Oriental, encontramos que el año 1935, su primer director, Alfredo Chang, hizo en ese año una visita a Chepén esa "...floreciente y simpática población..." donde le impresionó "...el sólido y bellísimo edificio propiedad de la Sociedad Comercial China..." lo que a su vez indicaba "...la excelente situación de que disfrutan los muy conocidos comerciantes (chinos)...". Esta apreciación no cambió durante años. Por eso en todas las décadas sucesivas no ha sido nunca extraño encontrar en nuestras páginas información sobre la colonia china chepenana...

El encargado de hacer la entrevista fue el Dr. Humberto Rodríguez Pastor (HRP), conocido investigador de la historia de los Hijos del Celeste Imperio en el Perú.

HRP. En estos últimos meses he estado en varios valles costeño revisando y recogiendo información histórica $y$ en ninguno hemos encontrado tanta población de origen chino como en el del Jequetepeque. ¿Cómo ubi$c a$, señor rector, Manuel Burga, el papel que ha tenido en todo este espacio geográfico del valle la importante y numerosa población china y sus descendientes?

Manuel Burga Díaz (MBD). Lo que recuerdo al respecto como historiador y como historiador del valle de Jequetepeque en su historia agraria es que la unidad rural productiva más moderna del valle era la hacienda Lurifico que tuvo varios propietarios muy conocidos en el ámbito nacional, que recibió el aporte de capitales extranjeros, y por eso pudo reunir la población china más considerable de todo el valle y probablemente la población más importante en comparación de los valles vecinos.

En la hacienda Lurifico funcionaba la Peruvian Sugar State que era la compañía azucarera de Augusto Dreyfus, allí fue donde la población china se concen- tró. Lo que yo puedo decir de la inmigración china en el valle del Jequetepeque es que fue una inmigración que se centró preferentemente en la hacienda Lurifico y que este latifundio extendió su influencia a otras haciendas del mismo valle de Jequetepeque. También puedo indicar que comparativamente la inmigración china con la inmigración vasca que se instaló en la hacienda Talambo, la primera dio mejores resultados en lo que se refiere a la creación de empresas modernas azucareras y, por el contrario, la inmigración vasca en Talambo no dio ningún resultado en haciendas arroceras.

Habría más cosas que indicar de la inmigración china, pero es una inmigración que cumplió los objetivos de aquellos que la habían organizado, es decir, producir azúcar, dinamizar la vida comercial local y crear un centro de producción agrícola importante en el valle. Eso es en cuanto se refiere a la parte de la historia agraria, estrictamente, historia de la inmigración china. 
Además lo que puedo decir — de lo que recuerdo es algo que nunca escribí y que no puse en mi libro-es que los inmigrantes chinos instalados en la hacienda Lurifico fueron consumidores de opio que se producía en la parte alta del Jequetepeque en la zona de Chota, Cutervo y que hay huellas de ese consumo. En los libros de la municipalidad de Guadalupe está asentado el permiso para la venta de opio que estaba destinada para los trabajadores chinos, es decir los chinos trajeron su fuerza de trabajo, sus costumbres, su cultura y también cosas muy ligadas a sus propias formas de recreación que era el consumo de opio ${ }^{1 .}$

Eso es lo que ocurrió con una parte importante de los chinos en la agricultura, pero hay otra parte sustancial de ellos en actividades urbanas y comerciales, y eso va junto con la importancia que iba cobrando Chepén en todo el valle en la época de los años 20 del siglo 20.

Si cuando en el año 1901-1902 se produce una crisis en el valle la Peruvian Sugar State empieza una crisis definitiva y 10 años más tarde en 1912-1913 ya solamente quedaba el recuerdo de la hacienda azucarera y de sus trabajadores chinos; éstos comenzaron a trasladarse a Chepén y empezó a acentuarse las tiendas de chinos en este poblado y es así como ocurre la transformación de los chinos de trabajadores rurales en comerciantes de tiendas pequeñas en Chepén y en otros centros poblados del valle como San Pedro de Lloc, Pacasmayo, Guadalupe, Pueblo Nuevo, etc. Esa es una parte no conocida en la historia de los chinos en Chepén, es una parte que me hubiera gustado entender porque toda mi niñez está vinculada a esas imágenes del comerciante chino de la gran tienda china.

HRP: Esa era la otra pregunta en cuanto a lo que Ud. ha vivido directamente con esa gente de origen chino a la que ha visto, cómo la observaba, cómo la percibía la gente de su generación, esa gente que la tenía muy próxima, Supongo que no era poco el volumen de personas de origen chino que se fue congregando alli donde Ud. ha crecido. Para empezar su respuesta, ¿hasta qué edad estuvo en Chepén?

MBD. Hasta los catorce años, pero en los años posteriores regresaba desde Lima durante los períodos de

1 La compra y venta de opio fue un comercio permitido por el Estado, tanto que a partir del año 1884 se convirtió en un Estanco controlado por ese mismo Estado. verano. Lo que recuerdo así nítidamente es la gran población de comerciantes chinos, comerciantes importantes en el negocio de venta de repuestos de carro, venta de abarrotes, tiendas de calidad, ferreterías. Gran parte del comercio de Chepén hasta los años 60 estaba en mano de los comerciantes chinos. Eso es interesante y eso tuvo repercusiones en la sociedad local. En Chepén había y hasta ahora debe haber, un club social donde se reunían los dueños de medianas propiedades que rodeaban a la población así como sus parientes y sus hijos e hijas, era el club social del pueblo de la elite social... También había el Club Unión que era de los comerciantes y que daba cabida a aquellos que venían de sectores no vinculados a la propiedad de la tierra y había también el club chino al cual muchos teníamos acceso no por cuestiones étnicas sino por cuestión de amistad ${ }^{2}$.

Muchos de mi generación tuvieron enamoradas chinas y, bueno, no nos parecía nada raro, nos parecía algo extraño nomás. Algo raro pero atractivo, había chinas muy guapas. Los amigos de mi generación siempre teníamos una curiosidad por eso pero yo diría, desde la época actual, recordando esos años, que la comunidad china hasta esos años 60 era bastante cerrada en lo que se refiere a relaciones matrimoniales y después progresivamente se fue abriendo más cuando entra en decadencia el club chino, y ello ocurre después de la revolución china, el año 1949, porque antes tenía mayor vitalidad de acuerdo a lo que yo escuché.

HRP. Pero seguramente ha tenido compañeros de origen chino en el colegio.

MBD. Había un colegio chino en Chepén, curiosamente por eso le digo, de esa colonia china yo no tengo amigos chinos de la infancia, mas bien tengo amigos chinos de la adolescencia cuando empiezan a abrirse los colegios fiscales.

HRP. Hay algo que conocemos los que somos sus amigos, que es respecto a sus orígenes chinos.

2 El Dr. Burga se está refiriendo al Chen Lhin Club. En realidad hubo muchas otras instituciones de las cuales la más importante fue la Sociedad Comercial China que congregaba a los chinos de todo el valle. Mencionemos de paso al Kuo Min Tang, partido político, el Colegio Pen Man, donde se procuró enseñar el idioma chino, la Cruz Roja China, establecida en los años de la 2da Guerra Mundial. 
MBD. Mi abuelo, Enrique Burga, tenía su padre que se llamó Bernardo Burga que había venido de Chota o de Cutervo, no lo sé exactamente. Mi abuelo Enrique Burga se instaló en el valle, luego se casó con mi abuela Andrea Rojas, que aun ignoro su apellido materno, ella tenía evidentes rasgos raciales asiáticos y lo más enigmático es que después he resuelto que mi abuela se apellidaba Rojas y sus hermanos apellidaban Chanamé ${ }^{3}$ y para mayor confusión sus primos cercanos se apellidaban Vera. Y todos eran de un árbol común pero de apellidos distintos y para mí eso siempre ha sido una cosa misteriosa que solo lo he entendido después cuando supe que muchos inmigrantes de origen chino adoptaban apellidos diversos sobre todo los de sus padrinos. Entonces, la familia de mi abuela que provenía de un tronco de inmigrantes chinos tenía apellidos diversos porque eran apellidos adoptados. Eso es lo que me gustaría en algún momento reconstruir, porque la abuela de la cual tengo una imagen de dulzura y sabiduría era evidentemente una abuela china, por su mońo, por su vestimenta y por sus zapatos que yo lo recuerde.

HRP. Quién sabe por eso algunas de sus cosas personales ella puede haberle transmitido. Tiene Ud. una disciplina que es un tanto oriental, tienes una persistencia y una constancia que también me parece son características que los chinos lo han demostrado de mil maneras. Claro que eso no va con la carga genética pero si va con una percepción contagiante de los parientes que tenemos cerca con los que convivimos $y$ en su caso puede haber resultado que la dulzura que le enseño a recibir su abuela haya ido junto con una forma de hacer y entender las cosas, de persistir para lograr los objetivos trazados; digamos que hasta llegar al rectorado.

MB. Probablemente de la abuela y del abuelo también provienen varias cosas mías. La abuela, para abundar en detalles de ella, era si bien racialmente china era culturalmente andina. De eso estoy convencido porque ella criaba sus cuyes, sus chanchos, hacía sus matanzas, invitaba a sus compadres, siempre había cada 6 u 8 meses matanza de cerdos en la casa, y reparto de comida, llegaba multitud de gente, de madres que venían. Pero a mi abuela nunca la escuché hablar chino, seguramente porque no lo sabía, nunca escuché que ella tuviera amigas chinas, por eso me parece que hubo una suerte de adopción y de introducción en un mundo diferente, como que las raíces étnicas de ella se perdieron en la historia y ella misma nunca pudo hablarnos de sus orígenes. Recuerdo yo a su hermana y la relación con su hermana, claro que uno nunca se acuerda mucho del abuelo, yo me acuerdo de ella y me acuerdo de todas esas partes misteriosas que algún día espero escribir.

HRP. Estas obligaciones del rectorado lamentablemente le están impidiendo sus investigaciones históricas ¿va a continuar de esta manera o va a distribuir su tiempo tal como hemos visto que la distribuye alguna otra gente que hace trabajo intelectual, destinan de tal a tal hora a sus investigaciones y de tal hora a tal hora al rectorado, y de tal hora a tal hora también para atender a los amigos?

MBD. Eso es lo que voy a hacer, voy a tratar de organizarme mejor, para no dejar de leer, para no dejar de investigar aunque sean cosas breves y no dejar, por supuesto, mis cursos. Ahora en estas semanas que he asumido el rectorado de San Marcos obligadamente he tenido que dejar cursos y lecturas y vivir casi en la oficina del rectorado, pero a medida que transcurra el tiempo pienso organizarme mejor, volver a mis lecturas y en lo posible prepararme para volver de manera mejor a mis investigaciones. Tengo tantos temas pendientes, tanto material inacabado que me gustaría escribirlos, volver a retomar mi trabajo y redactar. Este cargo de rector nunca lo pensé, siempre me imaginé que mi trabajo en mis ańos 50 sería como historiador pero la vida lo lleva a uno por donde debe ir, no por donde uno quiere ir.

\section{HRP. Gracias, señor rector.}

Esto no tiene nada de extraño, por entonces no era exigencia controlada llevar los apellidos de los padres. No poca gente, entre los sectores populares, utilizó los apellidos de sus padrinos. Y este fue el caso de miles de chinos en todo el territorio del país. 


\section{Valle del Jequetepeque Anotaciones sobre los Rojas}

\section{Por Humberto Rodríguez Pastor}

Las notas que siguen son resultado de la búsqueda de información sobre los chinos en diversos poblados del valle del Jequetepeque, registro que hemos realizado en estos últimos meses en parroquias, municipalidades y periódicos como parte de una amplia investigación sobre la chinización de los pueblos peruanos.

Es así que de la información de Chepén hemos hallado que el chino cristianizado Juan Flores fue pareja de la ascopana Sacramento Rojas; que Koc Chi fue el primer esposo de Victoria Rojas, pacasmaína nacida el ańo 1895, con quien tuvo un hijo, y que el segundo compromiso de ella fue con el comerciante Neptalí Li Kat Pum con quien tuvo al menos 4 hijos (3 hombres y una mujer). Victoria tuvo una hermana un año menor llamada Cristina quien estuvo casada con Situ Pon, un comerciante rico que condujo una empresa comercializadora de importante influencia en la región. A su vez Victoria y Cristina fueron hijas del chino Pedro Rojas y de Margarita Nieves. Él había adoptado el apellido Rojas y muy tempranamente enviudó por lo que decidió dejar a sus hijas en manos de una familia de Chepén donde crecieron y se criaron. Este chino tuvo un negocio de hospedaje en Tembladera, poblado que se halla en camino a Cajamarca, y fue bastante entusiasta y hasta alegre participante de la música y los bailes criollos.

De todas estas relaciones de pareja la que más interesa es la del asiático Atín Diéguez y las de sus esposas Lucía Chávez, primero, y Juana Rojas después. En su primera relación Atín tuvo una hija llamada Andrea que nació en el mes de diciembre de 1884. Ocho años después, posiblemente porque enviudó, lo encontramos comprometido con Juana Rojas con la que tuvo otra hija a la que llamó Agustina. Nuestra deducción final, ante la falta de información, es que Juana Rojas tuvo que criar a Andrea así como también a su hija Agustina y que por eso a la primera de las mencionadas le dio su apellido Rojas y es así que fue conocida de esta manera: Andrea Rojas. Ella ha podido ser la abuela del historiador Manuel Burga Díaz. 